\title{
A specific skin test: the best for both worlds?
}

\author{
Sandra Arend \\ From Immunodiagnosis of Tuberculosis: New Questions, New Tools \\ Virginia, VA, USA. 21-23 September 2008
}

For a new tuberculin skin test (TST) to be considered useful, it must meet several requirements including safety, a readable skin response, affordability, a high predictive value, and it cannot easily sensitize, depend on patient characteristics, nor depend on the Mycobacterium tuberculosis isolate. After review of previously conducted animal model studies, we designed a doubleblind randomized Phase 1 study comparing recombinant dimer ESAT-6 (rdESAT-6, Statens Serum Institut, Copenhagen, Denmark) to tuberculin as a skin test reagent in the diagnosis of TB. The goals of the study were to assess the safety of an intradermal method of administering the test and to determine the appropriate human dose. The study compared the administration of 2.0 TU PPD (standard dose of RT 23) to four doses of rdESAT- $6(0.01,0.1,1$, and $10 \mu \mathrm{g})$. The protocol also called for intra-subject randomization of the left and right forearm. Participants were enrolled in eight different groups. Four groups comprised five healthy controls each for the purpose of testing safety and sensitization issues. The other four groups comprised patients who had been treated for TB in order to determine safety and optimal dose. Several exclusion criteria were applied, including individuals who had received a TST test within the past year or had a known immune deficiency. During the 28-day trial, the guidelines called for 2 hours of close observation after administering the test on Day 0; clinical parameters, photography on Days 1 to 4 with quantiFERON testing of control subjects on Day 2 and lab and urine tests on Day 4; diary keeping on Days 5 to 28 with physical exam, lab and urine tests on Day 28 and quantiFERON testing of control groups.

In control groups, all four dosages of rdESAT-6 were administered with no serious side effects; transient redness occurred at 24 hours at the $10 \mu \mathrm{g}$ dose; and no

Correspondence: S.M.Arend@lumc.nl

Department of Infectious Diseases, Leiden University Medical Center, Leiden, The Netherlands indication of sensitization was measured in vitro. In the treated TB group, only doses of 0.01 and 0.1 of rdESAT6 were well-tolerated; equivalent responses to PPD and $0.1 \mu \mathrm{g}$ rdESAT- 6 were observed. Participants reported significant local side effects at $1 \mu \mathrm{g}$ of rdESAT-6. Results indicate that the new skin test is safe, produced a readable skin test response, did not easily sensitize, and is robust in all practical aspects. Further studies must be conducted on subjects ranging from individuals with active and latent TB, children, pregnant women, and patients who are immunocompromised.

Published: 17 December 2010

Reference

1. Arend SM, Franken WPJ, Aggerbeck H, Prins C, van Dissel JT, ThierryCarstensen B, Tingskov PN, Weldingh K, Andersen P: Double-blind randomized Phase I study comparing rdESAT-6 to tuberculin as skin test reagent in the diagnosis of tuberculosis infection. Tuberculosis 2007, doi:10.1016/j.tube.2007.11.004.

doi:10.1186/1753-6561-4-S3-O14

Cite this article as: Arend: A specific skin test: the best for both worlds? BMC Proceedings 2010 4(Suppl 3):014.

Submit your next manuscript to BioMed Central and take full advantage of:

- Convenient online submission

- Thorough peer review

- No space constraints or color figure charges

- Immediate publication on acceptance

- Inclusion in PubMed, CAS, Scopus and Google Scholar

- Research which is freely available for redistribution 